\title{
Root responses in chromosome segment substitution lines of rice 'KDML105' under early drought stress
}

\author{
Wanwipa Pinta ${ }^{1}$, Nimitr Vorasoot $^{1}$, Nuntawut Jongrungklang ${ }^{1}$, Jonaliza L. Saingliw ${ }^{2}$, \\ Theerayut Toojinda², and Jirawat Sanitchon ${ }^{1^{*}}$ \\ ${ }^{1}$ Khon Kaen University, Faculty of Agriculture, Khon Kaen 40002, Thailand. *Corresponding author (jirawat@kku.ac.th). \\ ${ }^{2}$ Rice Gene Discovery Laboratory, Kasetsart University, Kamphang Saen Campus, Nakhon Pathom 73140, Thailand.
}

Received: 5 December 2017; Accepted: 21 May 2018; doi 10.4067/S0718-58392018000200238

\begin{abstract}
Drought is a major cause of potential plant stress in areas of rain fed lowland rice (Oryza sativa L.) cultivation. The characteristics of the root system are important for rice plant adaptation and acquiring water under drought conditions. This study aims to evaluate the root responses contributing the plant adaptation to drought stress of 'KDML105' chromosome segment substitution lines (CSSLs). The rice genotypes were grown in PVC tubes. At $30 \mathrm{~d}$ after planting (DAP), the plants were subjected to two water regimes, well-watered and early drought stress. The two experiments were different in water status shown as relative water content and soil moisture content and classified as two stress condition in particular years i.e. mild and severe stress in 2013 and 2014 respectively. Shoot dry weight (SDW) and leaf area (LA) increased by mild stress while root dry weight (RDW) and total root length were increased by severe stress. The comparison between WW and DS in the percentage of SDW, RDW and LA showed that the CSSL\#6 was the great maintenance genotype in both 2013 and 2014 as well as the donor parent (DH212) while 'KDML105' showed a decreasing RDW in DS than WW. Root length density of all CSSLs was higher than 'KDML105' in the shallow soil layer (37\%), but CSSL\#12 was greatest in root length density at the deeper soil layers $(76.7 \%)$ under mild stress. Interestingly, CSSL\#1, \#4, \#5, \#6, \#12, \#14 and \#15 tended to produce a higher root depth $(59.6 \%, 52.0 \%, 53.6 \%, 58.6 \%, 52.7 \%, 49.7 \%$ and $53.3 \%$, respectively) at 30 to 90 cm of soil depth compared to 'KDML105' under severe stress. It is possible that several chromosome segments associated with root depth were introgressed from the donors (DH103 and DH212) through the breeding procedure, which can be used as a promising breeding material in Thailand.
\end{abstract}

Key words: Drought tolerance, Oryza sativa, recovery from drought, root system, soil moisture content, water deficit.

\section{INTRODUCTION}

More than half of the world's population consumes rice (Oryza sativa L.) as the main source of carbohydrates. About $70 \%$ of all rice cultivated areas are in the rain fed lowland environment which is at risk of water deficits during the growing season. The North and Northeast of Thailand are highly vulnerable to early and late wet-season drought, thus, appropriate drought tolerant rice varieties are required for these areas (Jongdee et al., 2006; Saleth et al., 2009). Therefore, this problem has become a major concern for rice production which could reduce productivity of $55 \%-68 \%$ in Northeast Thailand (Polthanee et al., 2014). These areas are the main rice growing areas for the popular aromatic varieties, including the well-known variety Khao Dawk Mali 105 ('KDML105'). This variety is moderately susceptible to drought stress. 
Due to its photoperiod sensitivity, 'KDML105' is only planted during the rainy season. Terminal drought reduced grain yield by 52\%-55\%, while intermittent could affect up to 23\%-33\% (Monkham et al., 2015) and these can greatly reduce reproductive growth and increase spikelet sterility (Kamoshita et al., 2008). At vegetative phase, drought reduces seedling growth and ultimately the production of rice when the water supply to root becomes difficult and transpiration rate becomes very high (Pandey and Shukla, 2015). Recovery growth after drought is generally accompanied by increasing tiller number (Wopereis et al., 1996) and leaf growth (Okami et al., 2015).

Enhancing drought resistance in rice is an important aspect for maintaining rice productivity. Not only physiological adaptation can improve drought tolerance, but also greater water extraction by deep rooting can contribute drought tolerance in several plants such as peanut (Junjittakarn et al., 2014), common bean (Polania et al., 2017) and rice (Nakata et al., 2011). Increasing the depth and density of roots are considered to be the main mechanisms for improving water uptake (Gowda et al., 2011). Root system development increases root length density, root DM and its function for effective and efficient water uptake under mild water deficit condition (Nakata et al., 2011). The root length and thickness are important traits which determine the uptake of water in the lower soil horizon, especially under drought stress conditions. During the early growth stage, root length, root growth and shoot DM are very sensitive to soil water status (Boonjung and Fukai, 1996). Promoting lateral root production, elongation, branching can thus eventually increase total root length in rice (Niones et al., 2012). Root depth and root length density have been identified as drought adaptive traits that can be used as selection criteria for drought tolerance.

In recent years, the use of genotypic variation for genomic research on drought tolerance mechanisms has been enhanced by the development of introgression lines from the segregating populations (Chen et al., 2006; Zhu et al., 2009; Xu et al., 2010; Shim et al., 2010; Furuta et al., 2014). Chromosome segment substitution lines (CSSLs) are a genetic resource that contains the genetic background of the recurrent parent, with overlapping chromosome segments of the donor parent. CSSLs can be used to identify target traits as well as minimize potential confounding effects due to variation in the genetic background of other traits (Saha et al., 2012).

In an earlier study, Kanjoo et al. (2012) developed the chromosome segment substitution lines (CSSLs), a series of near-isogenic lines (NILs) containing the fragment of drought tolerance traits in the genetic background of 'KDML105'. 'KDML105' (recurrent parent) is a Thai jasmine rice, is known as a premium aromatic-quality rice in the world rice market which has been a popular crop in rainfed lowlands area in Northeast of Thailand. However, it susceptible to drought stress in all growth stages especially early growth period. This variety was crossed with two double haploid (DH) lines (IR58586-F2-CA-31; DH103 and IR58586-F2-CA-143; DH212) as a donor parents by molecular backcrossing marker aided selection proceeds up to $\mathrm{BC}_{5} \mathrm{~F}_{4}$. The donor, $\mathrm{DH} 103$ was carried drought tolerant QTL (quantitative trait loci) on chromosome 8 while DH212 was carried drought tolerant QTL on chromosome 1, 3, 4 and 9. Each CSSL was contained single drought tolerance QTL. A set of CSSLs were screened for grain yield and yield components. The CSSL population was found to be greater in grain yield potential and yield components than 'KDML105' under late drought stress. However, limited information has been available for root responses to drought and rewatering of 'KDML105' CSSLs. The objective of this study was to investigate the traits, particularly root characters, in response to drought among 'KDML105' chromosome segment substitution lines. This information is helpful to determine future strategies for rice breeding in drought areas.

\section{MATERIALS AND METHODS}

\section{Plant materials and experimental design}

Khao Dawk Mali 105 (KDML105) is a Thai jasmine rice which known as a commercial premium aromatic quality rice in the world rice market. This variety has been a popular in Northeast of Thailand that mostly growing under rainfed lowlands condition. However, 'KDML105' is susceptible to drought stress especially early growth stage. Twenty chromosome segment substitution lines (CSSLs) were derived from a crossing between 'KDML105' and IR68586- $\mathrm{F}_{2}-\mathrm{CA}-143$ (hereafter designated as DH212) (cross 1) and 'KDML105' and IR68586- $\mathrm{F}_{2}-\mathrm{CA}-31$ (hereafter designated as DH103) (cross 2). Two donor parents, DH212 which has a good root system and DH103 which has high osmotic adjustment in a drought environment, were used to construct the CSSLs. The DH212 possesses alleles for drought tolerance QTL (DTQTL) on chromosomes 1,3,4, and 9, while the DH103 allele for DT-QTL located on chromosome 8 (Table 1) described 
Table 1. The chromosome segment substitution lines of 'KDML105' introgression with drought tolerance quantitative trait loci (QTL) and their parents were used in this study.

\begin{tabular}{|c|c|c|c|c|c|}
\hline Pedigree & Substitution segment & Chromosome & Donor & Size of DT segment & QTL \\
\hline RGD05164-11-MAS39 & RM212-RM3362 & 1 & DH212 & & \\
\hline RGD05164-11-MAS25 & RM212-RM3362 & 1 & DH212 & $49 \mathrm{cM}$ & PN, PH, LWP, \\
\hline RGD05164-11-MAS10 & RM212-RM3362 & 1 & DH212 & & DS, CT \\
\hline RGD05164-11-MAS18 & RM212-RM3362 & 1 & DH212 & & \\
\hline RGD05169-2-MAS12 & RM3413-RM3807 & 3 & DH212 & & \\
\hline RGD05162-3-MAS56 & RM3413-RM3807 & 3 & DH212 & $14.8 \mathrm{cM}$ & GY, HI, \\
\hline RGD05162-3-MAS44 & RM3413-RM3807 & 3 & DH212 & & DFAIG \\
\hline RGD05162-8-MAS41 & RM3413-RM3807 & 3 & DH212 & & \\
\hline RGD05131-4-MAS39 & RM142-RM559 & 4 & DH212 & & \\
\hline RGD05131-6-MAS5 & RM142-RM559 & 4 & DH212 & $53 \mathrm{cM}$ & GY, TSN \\
\hline RGD05128-10-MAS12 & RM142-RM559 & 4 & DH212 & & PSS, PN \\
\hline RGD05128-4-MAS40-MAS11 & RM142-RM559 & 4 & DH212 & & \\
\hline RGD06063-69-MAS24 & RM5353-RM3480 & 8 & DH103 & & \\
\hline RGD06064-6-MAS52 & RM5353-RM3480 & 8 & DH103 & $60 \mathrm{cM}$ & BY, PSS, \\
\hline RGD06064-6-MAS16-MAS2 & RM5353-RM3480 & 8 & DH103 & & $\mathrm{PN}, \mathrm{PH}$ \\
\hline RGD06064-26-MAS45-MAS8 & RM5353-RM3480 & 8 & DH103 & & \\
\hline RGD05160-6-MAS29 & RM242-RM205 & 9 & DH212 & & \\
\hline RGD05157-5-MAS8 & RM242 - RM205 & 9 & DH212 & $30 \mathrm{cM}$ & BY, HI, DS \\
\hline RGD05159-4-MAS56 & RM242-RM205 & 9 & DH212 & & \\
\hline RGD05159-4-MAS52-MAS4 & RM242-RM205 & 9 & DH212 & & \\
\hline KDML105 & & Recurrent parent & & & \\
\hline DH103 & & Donor parent & & & \\
\hline DH212 & & Donor parent & & & \\
\hline
\end{tabular}

DT: Drought tolerance; QTL: quantitative trait loci; PN: panicle number; PH: plan height; LWP: leaf water potential; DS: drought score: CT: canopy temperature; GY: grain yield; HI: harvest index; DFAIG: days to flowering after initiation of irrigation gradient; TSN: total spikelet number; PSS: percent spikelet sterility; BY: biological yield.

by Lanceras et al. (2004). In the first three generations, only three SSR markers per region were used to select lines that contain the donor allele (Kanjoo et al., 2012). In order to develop the CSSL population, backcrossing proceeds up to BC5 and the number of SSR markers were increased from 3 to at least 10 for each chromosome. CSSLs which are homozygous at the marker loci used in selection were selected in BC5F2, BC5F3 and BC5F4. At the end, the QTL introgressed into the CSSL population were actually derived from the original QTL mapped in the DH population which are possessed by the two DH lines used to cross with KDML105. Likewise, the QTL introgressed include traits for roots, leaf rolling, leaf drying, leaf water potential, osmotic adjustment (OA), grain yield and yield components which were dissected into small segments in order to study the mechanisms related to drought resistance. It was thus ensured that number of backcrossing and selfing should be enough to retain the background of KDML105 (recurrent parent) and homozygosity of advanced population.

The experiments were conducted under greenhouse conditions at the Field Crop Research Station $\left(16^{\circ} 28^{\prime}\right.$ N, $102^{\circ} 48^{\prime}$ E; 200 m a.s.1.), Khon Kaen University, Northeast Thailand during the rice growing season from July to December in 2013 and 2014. Details of cultivation were similar in both years. A factorial design was used with a combinations of two water regimes (well-watered and drought stress) and rice genotypes in a completely randomized design (CRD) with three replicates. In the well-watered treatment, the water depth was maintained at 3-5 cm above the soil surface throughout crop period. In the drought stress treatment, irrigation water was withheld over a $30 \mathrm{~d}$ period, from $30 \mathrm{~d}$ after planting (DAP) to 60 DAP in 2013 and from 35 DAP to 65 DAP in 2014. During this period, visual traits that indicated drought response were leaf rolling and relative water content.

Seeds of the rice breeding lines were grown in $0.2 \mathrm{~m}$ (diameter) $\times 1 \mathrm{~m}$ (length) PVC tubes in the greenhouse. The PVC tubes were split into two pieces lengthwise and held together using silicone and adhesive tape. Each PVC tube was filled with $40.5 \mathrm{~kg}$ dry sandy loam soil which was divided into nine layers. Each layer was filled with $4.5 \mathrm{~kg}$ dried soil to create a uniform bulk density $\left(1.43 \mathrm{~g} \mathrm{~cm}^{-3}\right)$ throughout the column. Individual healthy rice plants were allowed to grow in each tube. Weeds were controlled by hand weeding while insects were controlled by methomyl (S-methyl [EZ]-N[methylcarbamoyloxy] thioacetimidate, 40\% SP (Manate, Hitech Group Chemical Supply, Samut Prakan, Thailand). 


\section{Data collection}

The data was collected relative humidity $(\%)$, maximum and minimum air temperatures $\left({ }^{\circ} \mathrm{C}\right)$ by a data logger (EL-USBRT; DATAQ Instruments, Akron, Ohio, USA), and rainfall (mm) was recorded at a weather station near the experiment site. Although the experiment was grown under net greenhouse, the outside environment such as rainfall or relative humidity were affected.

The soil moisture content was recorded at 60 DAP by gravimetric method. Soil samples from four layers $(0-5,25-30$, $55-60$, and $85-90 \mathrm{~cm}$ ) were collected using a micro auger. The soil weight was measured using an electrical balance and then dried to constant weight in hot air oven (Memmert, Model 800, Schwabach, Geramany) at $105^{\circ} \mathrm{C}$ over $72 \mathrm{~h}$. Soil dry weights were recorded and soil moisture content was calculated as follows:

Soil moisture content $(\%)=$ Weight before drying - Soil dry weight $\times 100$ / Soil dry weight

Relative water content (RWC), an important characteristic that influences plant water status was determined in two fully expanded leaves. The leaves were cut approximately $10-15 \mathrm{~cm}$ from the tip and then cut into $5 \mathrm{~cm}$ sections. The fresh weights (FW) of the leaf samples were recorded, and then leaves were immersed in distilled water in a petri dish in a dark room for $4 \mathrm{~h}$. The leaves were removed and the surface water was blotted, after which the turgid weight (TW) was recorded. The samples were dried in a hot air oven at $80^{\circ} \mathrm{C}$ for $48 \mathrm{~h}$, or to constant dry weight (DW). The RWC was calculated using the following formula:

$$
\mathrm{RWC} \%=[(\mathrm{FW}-\mathrm{DW}) /(\mathrm{TW}-\mathrm{DW})] \times 100
$$

Tiller number (TN) was counted as the total number of tillers per plant. Leaf area (LA) was measured at the end of drought and recovery period in 2013 and 2014 using portable leaf area meter (CI-203 Handheld Laser Leaf Area Meter, CID Bio-Science, Camas, Washington, USA). Root samples were collected from both treatments. PVC tubes were split in half and root samples were taken to a depth of $90 \mathrm{~cm}$. The soil profile of each sample was separated into six layers: 0-15, $15-30,30-45,45-60,60-75$, and $75-90 \mathrm{~cm}$. The root material was separated from the soil by washing gently by spraying tap water on to $0.5 \mathrm{~mm}$ mesh. The washed roots were then stored in tap water at $10^{\circ} \mathrm{C}$. To collect root data, roots were spread out on acrylic trays $(200 \times 300 \mathrm{~mm}$ ) and scanned (Epson Perfection V700, Epson America, Long Beach, California, USA). The captured grayscale images were analyzed using WINRHIZO Pro 2004a software (Regent Instruments Inc., Quebec, Canada). Root length density (RLD) was calculated from the total root length ( $\mathrm{cm}$ ) at each depth, divided by the soil volume $\left(\mathrm{cm}^{3}\right)$.

The above ground plant part of each PVC tube were harvested by cutting. The freshly harvested material was then separated into culms and leaves. Root dry weight was measured after collecting root length data. The shoot and root samples were oven dried at $80^{\circ} \mathrm{C}$ for $48 \mathrm{~h}$ or until constant weight. Drought tolerant index (DTI) was calculated following drought stress/well-watered, for above ground traits and total root dry weight.

\section{Statistical analysis}

Statistical analysis of the data was performed using Statistix 10 (Analytical Software, Tallahassee, Florida, USA). ANOVA was used to determine treatment mean differences, following the procedure described by Gomez and Gomez (1984). The comparison of treatment means was made using least significant difference (LSD).

\section{RESULTS}

\section{The weather condition in experiments}

In the year 2013, the total amount of rainfall was $419.4 \mathrm{~mm}$, RH ranged from $56 \%$ to $90 \%$, maximum temperature ranged from 22.9 to $35.5^{\circ} \mathrm{C}$, and minimum temperature was $15.0-25.5{ }^{\circ} \mathrm{C}$ during experiment (Figure 1a). In 2014, the total amount of rainfall was $477.6 \mathrm{~mm}$, $\mathrm{RH}$ ranged from $52 \%$ to $83 \%$, maximum temperature ranged from 27.0 to $36.2^{\circ} \mathrm{C}$, and minimum temperature was $21-26{ }^{\circ} \mathrm{C}$ during season (Figure 1b). Early drought was imposed at 30 DAP in 2013 to create mild stress resulting a significant difference of soil moisture content among soil profile, which ranged from $4.8 \%$ to $18.9 \%$. In 2014 soil moisture content range was 4.0\%-6.3\%, which was lower than in 2013 (Figure 2). The conditions were classified as mild and severe moisture stress in 2013 and 2014, respectively. It was clearly shown that relative water content (RWC) under drought stress in 2014 was lower than in 2013 (Figure 3). 
Figure 1. Rainfall, relative humidity (RH), maximum (T-max) and minimum (T-min) temperatures from July to December of the year 2013 (a) and 2014 (b) at the meteorological station, Khon Kaen University, Thailand.
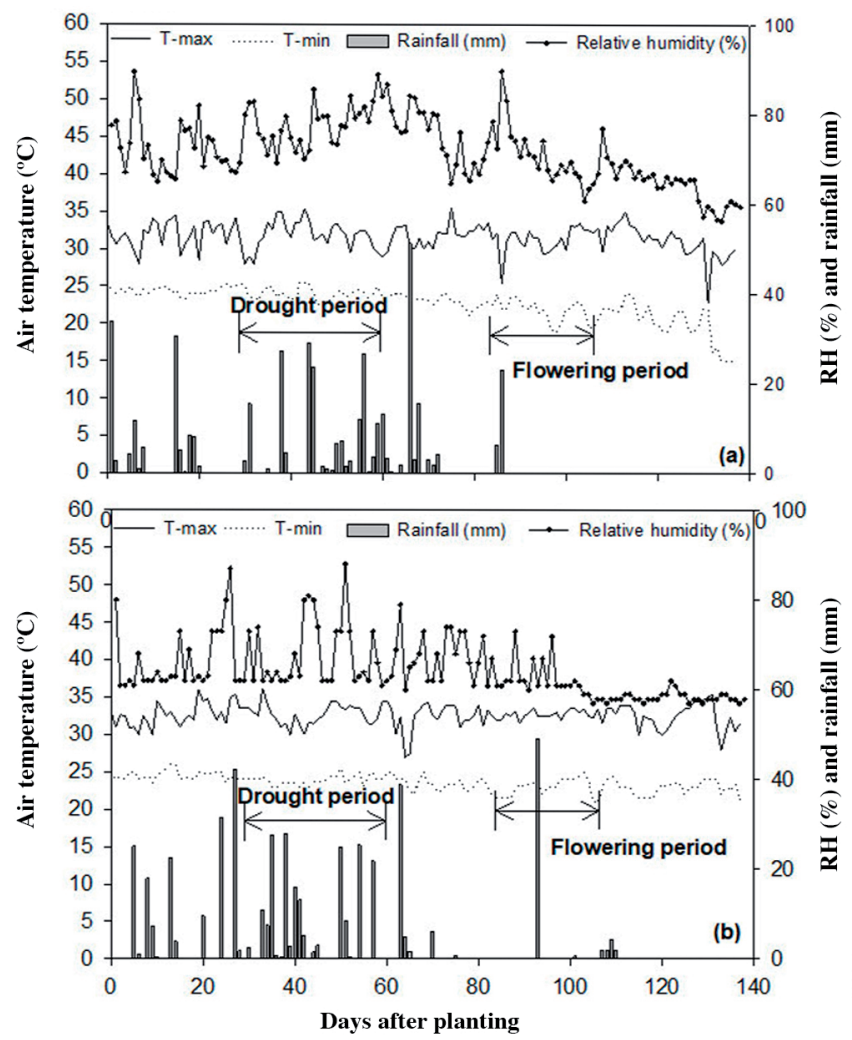

\section{Crop growth during drought period}

Leaf area (LA) of all CSSLs and their parents varied from 790 to $1671 \mathrm{~cm}^{2}$ plant $^{-1}$ when well-watered whereas this value varied from 1056 to $2429 \mathrm{~cm}^{2}$ plant ${ }^{-1}$ under early drought stress in 2013. Furthermore, LA varied from 2103 to 4369 and 567 to $1762 \mathrm{~cm}^{2}$ plant $^{-1}$ under well-watered and drought stress in 2014, respectively. Moreover, most of rice genotypes were significantly increased in LA under mild drought (2013) according to drought tolerance index (DTI) value (Table 2). It was different from the second year during which LA of all genotypes was decreased. The greatest LA under well-watered test was CSSL\#10 as well as 'KDML105' but under severe stress was CSSL\#12, while the good line consistency in LA was CSSL\#3 as depicted by the highest DTI.

In 2013, shoot dry weight (SDW) was significantly higher under drought than well-watered but root dry weight (RDW) was significantly lower in drought than in well-watered (Table 3). Mean of SDW of all CSSLs and their parents under well water varied from 9.9 to $20.7 \mathrm{~g} \mathrm{plant}^{-1}$ while it was 15.5 to $25 \mathrm{~g} \mathrm{plant}^{-1}$ under drought stress. CSSL\#11 (carried DT-QTL on chromosome 4) was higher in SDW than their parents. This indicated that mild drought stress at early rice growth stage could induce increasing of tiller number as well as leaf area (LA). Root dry weight ranged from 3.2 to $9.0 \mathrm{~g} \mathrm{plant}^{-1}$ and 2.1 to $7.0 \mathrm{~g} \mathrm{plant}^{-1}$ under well water and early drought stress, respectively. Root dry weight was thus, decreased significantly under drought stress (Table 3). The CSSL\#6 tended to be highest under drought stress. In 2014, shoot and root dry weights were considerably lower under early drought than well-watered (Table 3). The CSSL\#9 was greatest RDW under drought stress and well-watered.

The comparison of 30 DAP (before drought period) and 60 DAP (drought period) explained the plants increasing rate themselves under well-watered and drought stress (Table 4). Leaf area was increased by $95 \%$ in 2013 but only a 13\% increase in 2014. The severity of drought was the main effect on LA as well as SDW, which increased by $95 \%$ in 2013 and only by $79 \%$ in 2014. Furthermore, RDW was also increased in some genotypes in both 2013 and 2014. Root dry weight was decreased by 4\% in 2014 and 5\% in 2013. The CSSL\#6 was the greatest in RDW maintenance in both 2013 and 2014 
Figure 2. Soil moisture content at 30,60,90 d after planting (DAP) and at harvest (120 DAP) in experiments conducted at the Field Crop Research Station, Khon Kaen University, Thailand, during July-December in 2013 (a1 = well-watered; a2 = drought stressed), and 2014 (b1 = well-watered; b2 = drought stressed) at soil depths of 0-5, 25-30, 55-60 and 85-90 cm.
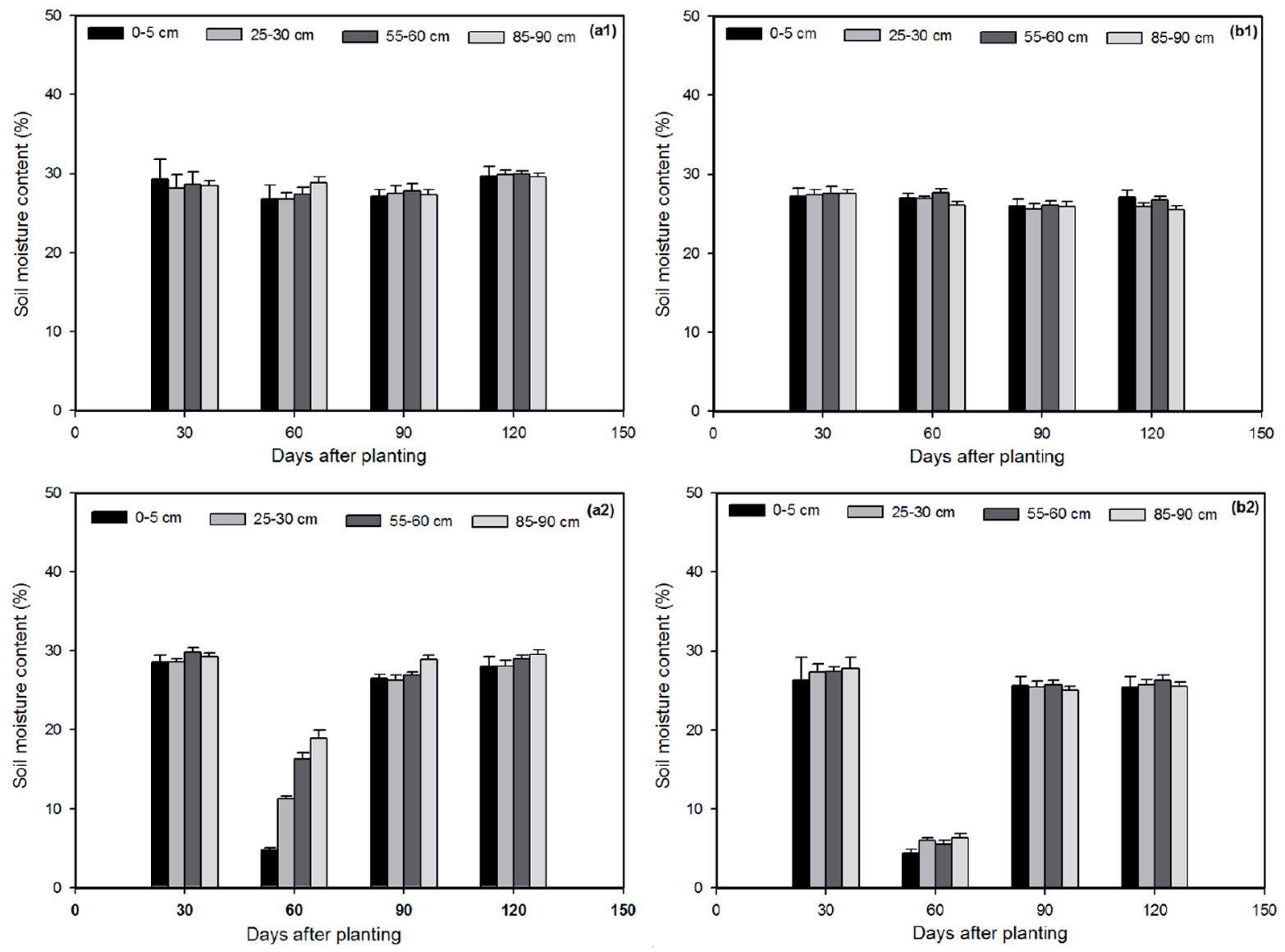

as well as the donor parent (DH212) while KDML105 was lower in RDW under stress (Table 4). The comparison between well-watered and drought stress depicted a decreasing in SDW, RDW and LA as affected by water deficit. However, some genotypes were increased in SDW, RDW and LA after drought imposed.

\section{Total root length and root length density during drought stress and rewatering}

Mean total root length did not differ between well water and drought stress at 30 DAP in both years, as well as 60 DAP of first year. However, the total root length under drought was greater than well-watered in the second year in which the drought was more severe. Upon rewatering, the rice under drought was rather induced to produce root branching and root depth than control treatment in both 2013 and 2014. However, total root length was nonsignificant at harvest (Figure 4).

Under well-watered, the root length density (RLD) mainly distributed in the $0-30 \mathrm{~cm}$ of soil depth and it was reduced with the increase of soil depth. In contrast, RLD increased in deeper soil layer and was mainly distributed in the 30-90 $\mathrm{cm}$ of soil layer under drought period (Figure 5) and rewatering in 2013 (Figure 6). Soil depths of 30-90 cm had higher $\%$ RLD than at $0-30 \mathrm{~cm} . \%$ RLD of DH103 at $30-90 \mathrm{~cm}$ soil depth was $81.8 \%$, higher than in CSSL\#12 (76.7\%), which is associated with drought tolerance QTL on chromosome 4. During the drought 30 to 60 DAP, RLD of CSSLs were mostly in the deeper soil layer $(30-90 \mathrm{~cm})$. On the other hand, root branching at soil surface was induced at rewatering (90 DAP). Therefore, the upper RLD ratio was greater than deeper soil layer at 90 DAP. 
Figure 3. Relative water content of 'KDML105' carrying different drought tolerance quantitative trait loci (DT-QTL) and their parents under well-watered and drought conditions in 2013 and 2014.

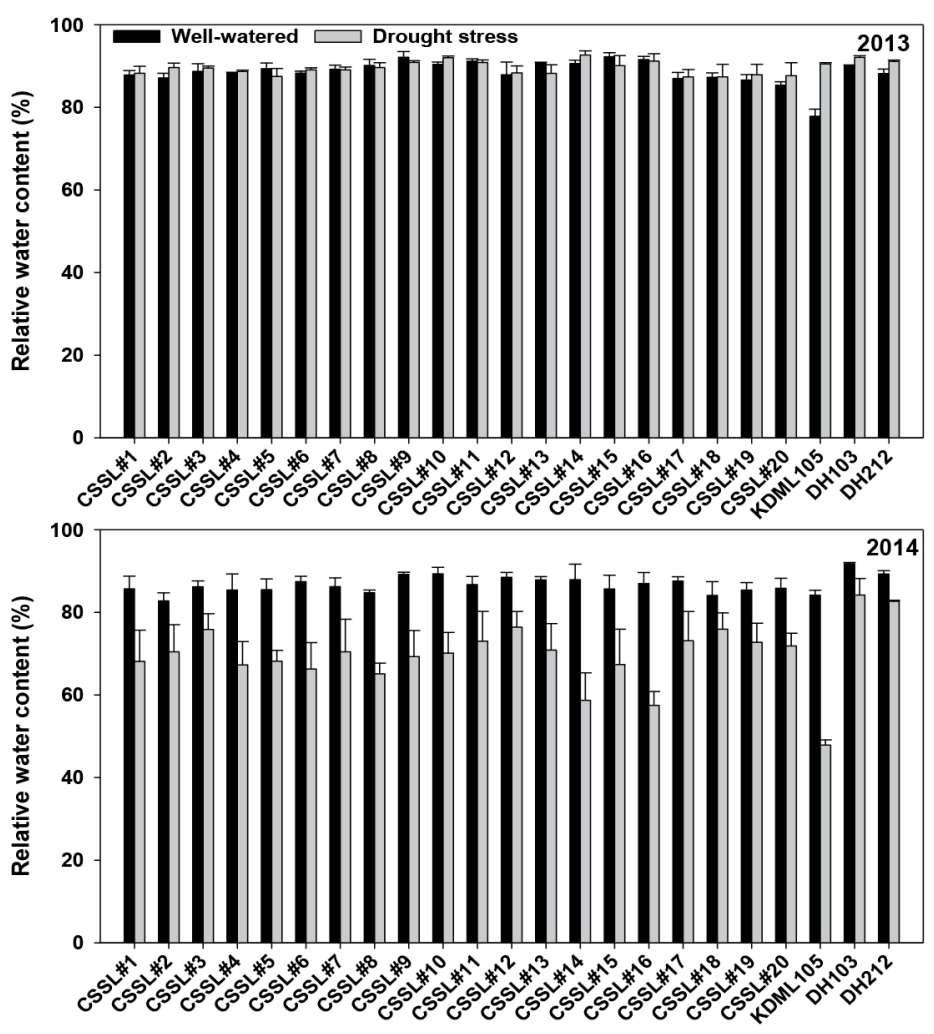

In the second year, after plants were imposed to drought stress, all CSSLs genotypes were high performance for deep rooting and branching at shallow depth. The root length density was highest in 0-15 $\mathrm{cm}$ soil depth and then reduced with the increase of soil depths (Figure 7). Under drought stress, the root length density increased in deeper soil layer and was mainly distributed in the 30-75 cm soil layer. Among the three parents, the two donors (DH103 and DH212) had a greater ability for root penetration than 'KDML105'. Under severe stress in 2014, the ratio of deeper root was lower than shallow root but after rewatering the root was regenerated as in 2013. However, roots of all CSSLs could penetrate deeper to extract water under drought stress as donor parents especially CSSL\#1, \#4,\#5,\#6,\#10, \#12 and \#15 (Figures 7 and 8).

\section{DISCUSSION}

\section{Water conditions}

In this study, severity of drought stress was identified from soil moisture content and relative water content (RWC). Soil moisture content reveal mild stress in 2013 and severe in 2014. The range of soil moisture content in 2013 was 4.8\%18.9\%, while 4.0\%-6.3\% in 2014. Nakata et al. (2011) defined a mild water deficit condition occurring when the soil moisture content was 20\%-25\% w/w. However, the severity of the water stress and its impact is dependent not only on soil moisture content but also its timing and duration (Kamoshita et al., 2008). In 2013 the soil moisture content was not uniform throughout the soil column during the drought period (30 d) and thus no reduction in RWC was observed compared with the well-watered treatment. The year 2013 was therefore classified as a year of mild water stress. In contrast, in 2014 low soil moisture content was observed through the stress period (30 d) at all soil levels. Although the stress duration was the same in both years $(30 \mathrm{~d})$, the amount of rainfall and humidity was different. The high humidity and rainfall affected the severity of drought even under greenhouse condition due to atmospheric humidity. DaMatta and Ramalho (2006) reported the effect of outside temperature on humidity in semi closed greenhouse (rainout shelter). Thus, 89\% humidity in 2013 affected a high RWC under drought condition. 
Table 2. Leaf area at $60 \mathrm{~d}$ after planting (drought stress period) of 'KDML105' chromosome segment substitution lines under well-watered (WW) and drought stress (DS) in 2013 and 2014.

\begin{tabular}{|c|c|c|c|c|c|c|}
\hline \multirow[b]{2}{*}{ Genotype } & \multicolumn{3}{|c|}{2013} & \multicolumn{3}{|c|}{2014} \\
\hline & WW & DS & DTI & WW & DS & DTI \\
\hline CSSL\#1 & 1242 & 1185 & 0.95 & $2718 \mathrm{ij}$ & $745 f-i$ & 0.27 \\
\hline CSSL\#2 & 1209 & 1211 & 1.00 & $3929 b-d$ & $607 \mathrm{ij}$ & 0.15 \\
\hline CSSL\#3 & 1114 & 1470 & 1.32 & $2244 \mathrm{k}$ & $1176 \mathrm{c}$ & 0.52 \\
\hline CSSL\#4 & 790 & 1305 & 1.65 & $3021 \mathrm{~g}-\mathrm{i}$ & $777 \mathrm{e}-\mathrm{h}$ & 0.26 \\
\hline CSSL\#5 & 948 & 1476 & 1.56 & 2868hi & $649 h-j$ & 0.23 \\
\hline CSSL\#6 & 1671 & 1566 & 0.94 & $2475 \mathrm{jk}$ & $820 \mathrm{e}-\mathrm{g}$ & 0.33 \\
\hline CSSL\#7 & 1504 & 1232 & 0.82 & 2925hi & $690 \mathrm{~g}-\mathrm{j}$ & 0.24 \\
\hline CSSL\#8 & 1277 & 1269 & 0.99 & $2103 \mathrm{k}$ & $646 h-j$ & 0.31 \\
\hline CSSL\#9 & 1562 & 1550 & 0.99 & 3611d-f & $675 h-j$ & 0.19 \\
\hline CSSL\#10 & 1499 & 1727 & 1.15 & $4369 a$ & $728 \mathrm{f}-\mathrm{i}$ & 0.17 \\
\hline CSSL\#11 & 1456 & 1850 & 1.27 & $3625 c-f$ & $660 h-j$ & 0.18 \\
\hline CSSL\#12 & 1440 & 2057 & 1.43 & $3708 \mathrm{c}-\mathrm{e}$ & $1762 \mathrm{a}$ & 0.48 \\
\hline CSSL\#13 & 1248 & 1289 & 1.03 & $3101 \mathrm{~g}-\mathrm{i}$ & $767 \mathrm{e}-\mathrm{h}$ & 0.25 \\
\hline CSSL\#14 & 1087 & 1421 & 1.31 & $3268 f-h$ & $678 \mathrm{~h}-\mathrm{j}$ & 0.21 \\
\hline CSSL\#15 & 1137 & 1360 & 1.20 & $4252 \mathrm{ab}$ & $1628 b$ & 0.38 \\
\hline CSSL\#16 & 992 & 1540 & 1.55 & $3203 \mathrm{gh}$ & $619 \mathrm{ij}$ & 0.19 \\
\hline CSSL\#17 & 1164 & 1405 & 1.21 & $3063 g-i$ & 896de & 0.29 \\
\hline CSSL\#18 & 1228 & 1353 & 1.10 & $4218 \mathrm{ab}$ & $980 \mathrm{~d}$ & 0.23 \\
\hline CSSL\#19 & 1268 & 2429 & 1.92 & $3425 \mathrm{e}-\mathrm{g}$ & $1001 d$ & 0.29 \\
\hline CSSL\#20 & 1394 & 1454 & 1.04 & 3188gh & $844 \mathrm{ef}$ & 0.26 \\
\hline KDML105 & 1026 & 1056 & 1.03 & $4017 a-c$ & $562 \mathrm{j}$ & 0.14 \\
\hline DH103 & 1131 & 1377 & 1.22 & $2696 \mathrm{ij}$ & $640 h-j$ & 0.24 \\
\hline DH212 & 1178 & 1599 & 1.36 & $2412 \mathrm{jk}$ & $580 \mathrm{j}$ & 0.24 \\
\hline $\operatorname{Max}$ & 1671 & 2429 & & 4369 & 1762 & \\
\hline Min & 790 & 1056 & & 2103 & 562 & \\
\hline Mean & 1242 & 1486 & & 3236 & 832 & \\
\hline F-test & ns & ns & & $* *$ & $* *$ & \\
\hline $\mathrm{CV}, \%$ & 39.2 & 33.7 & & 6.81 & 8.96 & \\
\hline \multicolumn{7}{|l|}{$\mathrm{P} \leq 0.05$} \\
\hline W & \multicolumn{2}{|c|}{$* *$} & \multicolumn{4}{|c|}{$* *$} \\
\hline G & \multicolumn{2}{|c|}{ ns } & \multicolumn{4}{|c|}{$* *$} \\
\hline $\mathrm{W} \times \mathrm{G}$ & \multicolumn{2}{|c|}{ ns } & \multicolumn{4}{|c|}{$* *$} \\
\hline $\mathrm{CV}, \%$ & \multicolumn{2}{|c|}{36.17} & \multicolumn{4}{|c|}{8.08} \\
\hline
\end{tabular}

*,**Significant at the 0.05 and 0.01 probability levels, respectively.

ns: Nonsignificant; DTI: drought tolerance index; W: water level; G: genotype.

\section{Crop growth during drought period}

Early stage of plants experiencing drought stress affected crop growth both above and underground plant parts. The genotypes showed variation for several drought tolerance related traits. Early season drought could significantly increase the economic yield (Okami et al., 2015). A high relative water content (RWC) has been previously reported to improve the ability of plants to extract soil water for increased water uptake associated with the aquaporin gene PIPI and RWC3 in maize, which resulted in improvement of root water uptake and consequently enhancement of drought tolerance (Comas et al., 2013). Leaf area (LA) growth during severe stress (2014) was reduced (Table 2). This is possibly due to a leaf rolling from the plant to minimize transpiration (Pandey and Shukla, 2015). In 2013, plants were experienced to mild and aerobic soil. Uphoff et al. (2015) reported an increasing of LA due to greater number and size of leaves. Relative water content of plant indicated that plant water status was not affected by drought. Similarly, shoot dry weight (SDW) was not reduced under mild stress but the root was sensitive to drought (Table 3). The reduction of root dry weight (RDW) under mild stress caused by the alteration of sugar partitioning among sinks. Some sinks such as root favors in case of mineral deficiency (Lemoine et al., 2013). Moreover, the increase in LA under recovery from drought might be a process from the plant to promote leaf expansion or renewal of tiller number. Nevertheless, severe stress during the reproductive stage has a greater effect on grain yield than mild stress, due to the reducing of tiller number (Hazra and Chandra, 2014), LA (Cabuslay et al., 2002) and photosynthesis (Chaves et al., 2009). Both root and shoot dry weight are important characters 
Table 3. Shoot and root dry weight at $60 \mathrm{~d}$ after planting (drought stress period) of 'KDML105' chromosome segment substitution lines (CSSLs) under well-watered (WW) and drought stress (DS) in 2013 and 2014.

\begin{tabular}{|c|c|c|c|c|c|c|c|c|c|c|c|c|}
\hline \multirow[b]{3}{*}{ Genotype } & \multicolumn{6}{|c|}{2013} & \multicolumn{6}{|c|}{2014} \\
\hline & \multicolumn{3}{|c|}{ Shoot dry weight } & \multicolumn{3}{|c|}{ Root dry weight } & \multicolumn{3}{|c|}{ Shoot dry weight } & \multicolumn{3}{|c|}{ Root dry weight } \\
\hline & WW & DS & DTI & WW & DS & DTI & WW & DS & DTI & WW & DS & DTI \\
\hline CSSL\#1 & 14.7 & $15.5 \mathrm{e}$ & 1.05 & 5.6a-d & 2.3 & 0.42 & $43.6 \mathrm{ef}$ & $27.8 \mathrm{~d}-\mathrm{g}$ & 0.6 & $7.6 e-i$ & $7.3 \mathrm{~d}-\mathrm{f}$ & 0.97 \\
\hline CSSL\#2 & 15.1 & $15.7 \mathrm{e}$ & 1.04 & $6.2 \mathrm{a}-\mathrm{d}$ & 2.7 & 0.44 & $38.1 \mathrm{gf}$ & $26.0 \mathrm{e}-\mathrm{h}$ & 0.7 & 4.91-o & $7.8 \mathrm{~b}-\mathrm{d}$ & 1.61 \\
\hline CSSL\#3 & 13.6 & $16.7 \mathrm{c}-\mathrm{e}$ & 1.23 & $6.6 \mathrm{a}-\mathrm{d}$ & 2.7 & 0.41 & $31.3 \mathrm{~h}$ & $25.1 \mathrm{gh}$ & 0.8 & $6.2 \mathrm{i}-\mathrm{m}$ & $6.7 f-h$ & 1.09 \\
\hline CSSL\#4 & 9.9 & $15.5 \mathrm{e}$ & 1.57 & $4.4 \mathrm{~cd}$ & 3.1 & 0.70 & $45.0 \mathrm{e}$ & $25.5 \mathrm{f}-\mathrm{h}$ & 0.6 & $6.5 \mathrm{~h}-1$ & $6.6 \mathrm{~g}-\mathrm{i}$ & 1.01 \\
\hline CSSL\#5 & 14.5 & $21.5 \mathrm{a}-\mathrm{c}$ & 1.49 & $3.2 \mathrm{~d}$ & 5.2 & 1.63 & $32.2 \mathrm{gh}$ & $32.3 \mathrm{ab}$ & 1.0 & $9.2 \mathrm{c}-\mathrm{f}$ & $5.8 \mathrm{j}$ & 0.64 \\
\hline CSSL\#6 & 13.9 & $21.1 \mathrm{a}-\mathrm{d}$ & 1.51 & $5.6 \mathrm{a}-\mathrm{d}$ & 7.0 & 1.25 & $44.2 \mathrm{ef}$ & $32.1 \mathrm{a}-\mathrm{c}$ & 0.7 & $9.0 c-f$ & $8.1 \mathrm{bc}$ & 0.90 \\
\hline CSSL\#7 & 20.3 & $18.8 b-e$ & 0.92 & $9.0 \mathrm{a}$ & 3.4 & 0.38 & $51.5 b-d$ & $28.1 \mathrm{~d}-\mathrm{g}$ & 0.6 & $8.4 \mathrm{~d}-\mathrm{g}$ & $6.8 \mathrm{f}-\mathrm{h}$ & 0.81 \\
\hline CSSL\#8 & 17.7 & 16.0de & 0.90 & $7.1 \mathrm{a}-\mathrm{c}$ & 2.1 & 0.30 & $42.6 \mathrm{ef}$ & $29.1 \mathrm{c}-\mathrm{e}$ & 0.7 & 4.3 no & $6.8 \mathrm{f}-\mathrm{h}$ & 1.56 \\
\hline CSSL\#9 & 20.7 & 20.6a-e & 1.00 & $8.2 \mathrm{ab}$ & 2.3 & 0.29 & $62.5 \mathrm{a}$ & $32.7 \mathrm{a}$ & 0.5 & $11.9 \mathrm{a}$ & 7.1e-g & 0.60 \\
\hline CSSL\#10 & 16.5 & $22.7 \mathrm{ab}$ & 1.37 & $5.3 \mathrm{~b}-\mathrm{d}$ & 2.9 & 0.56 & $61.7 \mathrm{a}$ & $29.1 \mathrm{c}-\mathrm{e}$ & 0.5 & $6.6 \mathrm{~g}-\mathrm{k}$ & $7.5 \mathrm{de}$ & 1.13 \\
\hline CSSL\#11 & 17.8 & $25.0 \mathrm{a}$ & 1.40 & $5.9 \mathrm{a}-\mathrm{d}$ & 3.0 & 0.50 & $53.5 \mathrm{bc}$ & $28.7 \mathrm{de}$ & 0.5 & $9.6 b-d$ & $4.6 \mathrm{kl}$ & 0.48 \\
\hline CSSL\#12 & 18.7 & $21.1 \mathrm{a}-\mathrm{d}$ & 1.13 & $7.6 \mathrm{a}-\mathrm{c}$ & 3.6 & 0.48 & $43.4 \mathrm{ef}$ & $28.0 \mathrm{~d}-\mathrm{g}$ & 0.6 & 3.50 & 4.11 & 1.17 \\
\hline CSSL\#13 & 17.7 & $16.3 \mathrm{c}-\mathrm{e}$ & 0.92 & $6.5 a-d$ & 2.8 & 0.43 & $45.0 \mathrm{e}$ & $18.5 \mathrm{i}$ & 0.4 & 11.1ab & $6.7 \mathrm{gh}$ & 0.60 \\
\hline CSSL\#14 & 14.2 & $18.1 \mathrm{~b}-\mathrm{e}$ & 1.27 & $6.4 \mathrm{a}-\mathrm{d}$ & 3.1 & 0.48 & $24.1 \mathrm{i}$ & $27.4 \mathrm{~d}-\mathrm{g}$ & 1.1 & $9.0 \mathrm{c}-\mathrm{f}$ & $8.2 \mathrm{~b}$ & 0.90 \\
\hline CSSL\#15 & 14.7 & $17.2 \mathrm{c}-\mathrm{e}$ & 1.17 & $4.8 \mathrm{~b}-\mathrm{d}$ & 2.2 & 0.46 & $52.8 \mathrm{bc}$ & $32.9 \mathrm{a}$ & 0.6 & $10.7 \mathrm{a}-\mathrm{c}$ & $5.5 \mathrm{j}$ & 0.52 \\
\hline CSSL\#16 & 13.9 & $19.7 b-e$ & 1.42 & $5.5 \mathrm{a}-\mathrm{d}$ & 2.4 & 0.43 & $35.3 \mathrm{gh}$ & $23.3 \mathrm{~h}$ & 0.7 & $6.5 \mathrm{~h}-1$ & $8.8 \mathrm{a}$ & 1.36 \\
\hline CSSL\#17 & 18.5 & $19.0 \mathrm{~b}-\mathrm{e}$ & 1.03 & $6.2 \mathrm{a}-\mathrm{d}$ & 3.2 & 0.51 & 46.1de & $29.3 b-d$ & 0.6 & $7.1 \mathrm{~g}-\mathrm{k}$ & $6.1 \mathrm{ij}$ & 0.86 \\
\hline CSSL\#18 & 17.1 & $18.9 b-e$ & 1.11 & $6.7 \mathrm{a}-\mathrm{d}$ & 2.6 & 0.39 & $52.0 \mathrm{~b}-\mathrm{d}$ & $32.3 \mathrm{ab}$ & 0.6 & $5.3 \mathrm{k}-\mathrm{n}$ & $6.9 \mathrm{f}-\mathrm{h}$ & 1.29 \\
\hline CSSL\#19 & 15.8 & $17.8 \mathrm{~b}-\mathrm{e}$ & 1.13 & $6.2 \mathrm{a}-\mathrm{d}$ & 2.6 & 0.42 & $44.8 \mathrm{e}$ & 28.6d-f & 0.6 & $9.3 c-e$ & 7.1e-g & 0.77 \\
\hline CSSL\#20 & 19.0 & $19.9 b-e$ & 1.05 & $6.8 \mathrm{a}-\mathrm{d}$ & 2.8 & 0.42 & $46.2 \mathrm{de}$ & $31.9 \mathrm{a}-\mathrm{c}$ & 0.7 & $7.4 \mathrm{f}-\mathrm{j}$ & $5.6 \mathrm{j}$ & 0.77 \\
\hline KDML105 & 14.7 & $16.9 \mathrm{c}-\mathrm{e}$ & 1.15 & $4.0 \mathrm{~cd}$ & 3.1 & 0.78 & $54.3 b$ & $31.7 \mathrm{a}-\mathrm{c}$ & 0.6 & $8.0 \mathrm{~d}-\mathrm{h}$ & $6.4 \mathrm{hi}$ & 0.80 \\
\hline DH103 & 13.0 & $16.8 \mathrm{c}-\mathrm{e}$ & 1.29 & $3.2 \mathrm{~d}$ & 2.1 & 0.66 & $47.2 \mathrm{c}-\mathrm{e}$ & $26.2 \mathrm{~d}-\mathrm{h}$ & 0.6 & $4.5 \mathrm{~m}-\mathrm{o}$ & $4.7 \mathrm{k}$ & 1.06 \\
\hline DH212 & 13.7 & $16.6 c-e$ & 1.21 & $4.4 \mathrm{~cd}$ & 2.8 & 0.63 & $42.4 \mathrm{ef}$ & $28.1 \mathrm{~d}-\mathrm{g}$ & 0.7 & $5.7 \mathrm{j}-\mathrm{n}$ & $7.6 c-e$ & 1.33 \\
\hline Max & 20.7 & 25.0 & & 9.0 & 7.0 & & 62.5 & 32.9 & & 11.9 & 8.8 & \\
\hline Min & 9.9 & 15.5 & & 3.2 & 2.1 & & 24.1 & 18.5 & & 3.5 & 4.1 & \\
\hline Mean & 15.9 & 18.6 & & 5.8 & 3.0 & & 45.2 & 28.5 & & 7.5 & 6.6 & \\
\hline F-test & $\mathrm{ns}$ & $* *$ & & $*$ & ns & & $* *$ & $* *$ & & $* *$ & $* *$ & \\
\hline $\mathrm{CV}, \%$ & 26.9 & 14.44 & & 30.83 & 55.12 & & 7.77 & 5.74 & & 12.79 & 4.96 & \\
\hline$P \leq 0.05$ & & & & & & & & & & & & \\
\hline W & \multicolumn{3}{|c|}{$* *$} & \multicolumn{3}{|c|}{$* *$} & \multicolumn{2}{|l|}{$* *$} & \multicolumn{4}{|c|}{$* *$} \\
\hline $\mathrm{G}$ & \multicolumn{2}{|c|}{$* *$} & \multicolumn{4}{|c|}{ ns } & \multicolumn{2}{|l|}{$* *$} & \multicolumn{4}{|c|}{$* *$} \\
\hline $\mathrm{W} \times \mathrm{G}$ & \multicolumn{2}{|c|}{ ns } & \multicolumn{4}{|c|}{$*$} & \multicolumn{2}{|l|}{$* *$} & \multicolumn{4}{|c|}{$* *$} \\
\hline $\mathrm{CV}, \%$ & \multicolumn{2}{|c|}{20.73} & \multicolumn{4}{|c|}{39.14} & \multicolumn{2}{|c|}{7.44} & \multicolumn{4}{|c|}{10.18} \\
\hline
\end{tabular}

***Significant at 0.05 and 0.01 probability levels, respectively.

DTI: Drought tolerance index; ns: nonsignificant; W: water level; G: genotype.

that have been shown to be correlated with grain yield under stress conditions (Kanbar et al., 2009). This study showed that the severity of drought was the main effect on plant production. The root was the important part for survival as showed in the second year, experiment when RDW was greater whereas SDW was reduced substantially. CSSL\#2,\#8 and \#16 were great adaptation in RDW under severe drought stress as showed in high drought tolerance index (DTI) value.

After recovery from drought period, SDW did not differ between water regimes and no interaction was observed. Upon rewatering, the rice regenerates active tiller and leaf elongation that make them to be the same as control. This is similar to the result reported by Kameoka et al. (2016).

\section{Root response during drought stress and rewatering}

Rice root response to the early drought was to rather grow in deeper soil layers to extract soil water than produce root branching in top soil (Figures 5 and 7). It is most likely that rewatering induced root branching and root depth in CSSLs compared to control treatment (Figures 6 and 8). This suggested that mild drought stress at early rice growth stage might produce more root growth in deeper layer than shallow depth. In contrast, root growth under well water produced more branching in top soil. This result matches with previous findings: Lateral root branching was inhibited in aerobic rice compared with flooded rice (Kato and Okami, 2010). In addition, root traits contributed improvement of above ground traits (Kanjoo et al., 2012). Deep root systems associated with the xylem diameter which influences the extraction of 
Table 4. Plant increasing rate (\%) including shoot dry weight (SDW), root dry weight (RDW) and leaf area (LA) of 'KDML105' chromosome segment substitution lines (CSSLs) during drought period in 2013 and 2014.

\begin{tabular}{|c|c|c|c|c|c|c|c|c|c|c|c|c|}
\hline \multirow[b]{3}{*}{ Genotype } & \multicolumn{6}{|c|}{2013} & \multicolumn{6}{|c|}{2014} \\
\hline & \multicolumn{2}{|c|}{ SDW } & \multicolumn{2}{|c|}{ RDW } & \multicolumn{2}{|c|}{ LA } & \multicolumn{2}{|c|}{ SDW } & \multicolumn{2}{|c|}{ RDW } & \multicolumn{2}{|c|}{ LA } \\
\hline & WW & DS & WW & $\mathrm{DS}$ & WW & $\overline{\mathrm{DS}}$ & WW & DS & WW & $\mathrm{DS}$ & WW & DS \\
\hline CSSL\#1 & 94.0 & 90.8 & 96.1 & 87.7 & 94.4 & 93.8 & 88.7 & 86.8 & 73.2 & 78.9 & 81.3 & -17.6 \\
\hline CSSL\#2 & 94.3 & 94.7 & 97.2 & 88.6 & 93.2 & 93.4 & 84.9 & 83.7 & 70.5 & 81.5 & 80.6 & 21.8 \\
\hline CSSL\#3 & 94.7 & 96.0 & 97.5 & 94.1 & 90.7 & 95.0 & 88.6 & 82.6 & 81.9 & 84.6 & 74.8 & 55.9 \\
\hline CSSL\#4 & 95.8 & 95.2 & 97.4 & 92.1 & 89.0 & 94.6 & 87.7 & 77.1 & 80.4 & 65.0 & 81.7 & 17.0 \\
\hline CSSL\#5 & 95.4 & 93.7 & 92.8 & 93.5 & 93.0 & 96.0 & 63.1 & 84.0 & 73.2 & 65.6 & 55.1 & 14.0 \\
\hline CSSL\#6 & 93.2 & 96.6 & 95.4 & 97.4 & 94.4 & 98.6 & 81.1 & 82.9 & 68.9 & 76.6 & 67.4 & 30.7 \\
\hline CSSL\#7 & 95.9 & 95.0 & 97.0 & 92.2 & 97.0 & 94.7 & 87.0 & 75.1 & 73.5 & 72.9 & 76.8 & 1.2 \\
\hline CSSL\#8 & 94.5 & 96.1 & 96.7 & 94.2 & 93.5 & 95.9 & 84.4 & 80.7 & 51.0 & 69.1 & 67.7 & 1.2 \\
\hline CSSL\#9 & 96.3 & 96.5 & 97.4 & 90.6 & 95.2 & 94.8 & 88.4 & 70.9 & 83.5 & 60.2 & 74.8 & -48.2 \\
\hline CSSL\#10 & 93.0 & 95.5 & 93.7 & 91.5 & 95.3 & 96.5 & 89.2 & 83.6 & 70.1 & 77.7 & 77.8 & 27.3 \\
\hline CSSL\#11 & 96.7 & 96.9 & 97.5 & 92.1 & 94.6 & 97.0 & 86.7 & 72.9 & 75.1 & 49.3 & 77.3 & -46.2 \\
\hline CSSL\#12 & 95.4 & 96.2 & 96.2 & 93.7 & 95.1 & 97.2 & 91.9 & 82.5 & 73.8 & 60.4 & 90.5 & 74.8 \\
\hline CSSL\#13 & 94.7 & 93.6 & 95.4 & 89.1 & 93.9 & 92.6 & 86.0 & 49.3 & 81.2 & 74.9 & 80.7 & 9.6 \\
\hline CSSL\#14 & 93.2 & 95.6 & 95.6 & 91.7 & 92.6 & 96.6 & 73.6 & 76.8 & 77.9 & 68.8 & 81.0 & -37.6 \\
\hline CSSL\#15 & 95.9 & 94.5 & 96.5 & 85.9 & 93.4 & 93.9 & 85.5 & 75.2 & 83.5 & 56.1 & 79.4 & 43.6 \\
\hline CSSL\#16 & 94.7 & 94.6 & 95.2 & 86.9 & 90.5 & 95.0 & 83.2 & 79.1 & 69.1 & 79.4 & 78.3 & 14.0 \\
\hline CSSL\#17 & 95.0 & 95.3 & 96.9 & 92.2 & 93.5 & 96.8 & 85.0 & 80.8 & 76.2 & 72.4 & 77.3 & 40.7 \\
\hline CSSL\#18 & 92.2 & 95.5 & 96.1 & 87.5 & 97.0 & 96.0 & 87.4 & 80.2 & 70.5 & 72.1 & 78.3 & 23.4 \\
\hline CSSL\#19 & 95.2 & 93.1 & 96.0 & 88.0 & 92.0 & 97.9 & 86.7 & 80.4 & 77.1 & 71.8 & 80.8 & 42.3 \\
\hline CSSL\#20 & 94.7 & 95.2 & 96.5 & 91.8 & 94.2 & 95.4 & 87.3 & 82.0 & 77.1 & 60.4 & 82.6 & 21.2 \\
\hline KDML105 & 93.6 & 91.5 & 93.5 & 86.4 & 92.9 & 92.5 & 88.2 & 81.8 & 75.5 & 70.0 & 82.8 & 0.9 \\
\hline DH103 & 97.3 & 98.4 & 97.1 & 96.3 & 92.7 & 94.9 & 93.1 & 87.8 & 78.4 & 77.4 & 86.9 & 39.1 \\
\hline DH212 & 95.4 & 97.2 & 95.8 & 94.2 & 94.6 & 94.7 & 90.1 & 80.0 & 70.9 & 76.0 & 77.7 & -26.5 \\
\hline Mean & 94.8 & 95.1 & 96.1 & 91.2 & 93.6 & 95.4 & 85.6 & 79.0 & 74.5 & 70.5 & 77.9 & 13.2 \\
\hline
\end{tabular}

available soil water to maintain crop growth (Comas et al., 2013). However, after rewatering, the CSSLs were performed rapidly in root branching in the top soil layer. Recovery ability is the most important trait related to early season drought, since it contributes to high grain yield (Kim and Kim, 2009). Kameoka et al. (2016) found that 'KDML105' was not able to maintain root length density in deep soil layer, but it did have a good root branching in the upper soil layer. In contrast, both donor parents were not be able to produce new root after rewatering at top soil layer but they responded with roots at deeper soil layers. The advantage of deeper roots was a sustainable grain yield compared to shallow root, under mild stress (Siangliw et al., 2007; Kanjoo et al., 2012). Moreover, soil management by ridge tillage is greater method for increasing yield of rice due to these was increased photosynthesis and also enhanced root character such as root number, root activity and oxidation enzyme of rice resulting to increased effective panicle number and grain yield. Moreover, this can be enhanced aerenchyma during early stage and suitable for fields with water shortage at early stages (Yao, 2015). The plant type of these CSSLs are similar to 'KDML105', with a large plant size, plant height and grain yield (data not shown). Accordingly, pyramiding of several QTLs that confer root traits into elite variety would be a prerequisite for improvement of deep root growth (Gowda et al., 2011). The CSSLs in this study showed an ability for root recovery under both conditions. Moreover, all of the CSSLs showed the same ability as 'KDML105' in root regeneration and root length density after rewatering, and were similar in root depth to DH103 and DH212 which were important traits for unpredictable water deficit condition.

\section{CONCLUSIONS}

The responses of chromosome segment substitution lines (CSSLs) carrying different drought tolerance - quantitative trait loci regions on chromosomes $1,3,4,8$, and 9 to drought were evaluated on the root traits and some agronomic traits. The CSSL\#6 was great in maintenance of shoot dry weight (SDW), root dry weight (RDW) and leaf area (LA) under early drought stress as well as donor parents while 'KDML105' was lower in RDW under drought stress than wellwatered. Root length density (RLD) at deeper layers shows to be greater in CSSL\#12 than 'KDML105' under mild stress. 
Figure 4. Average total root length of rice at 30,60 (drought period), 90 (rewatering) days after planting (DAP) and harvesting under well-watered and drought stress in 2013 and 2014.

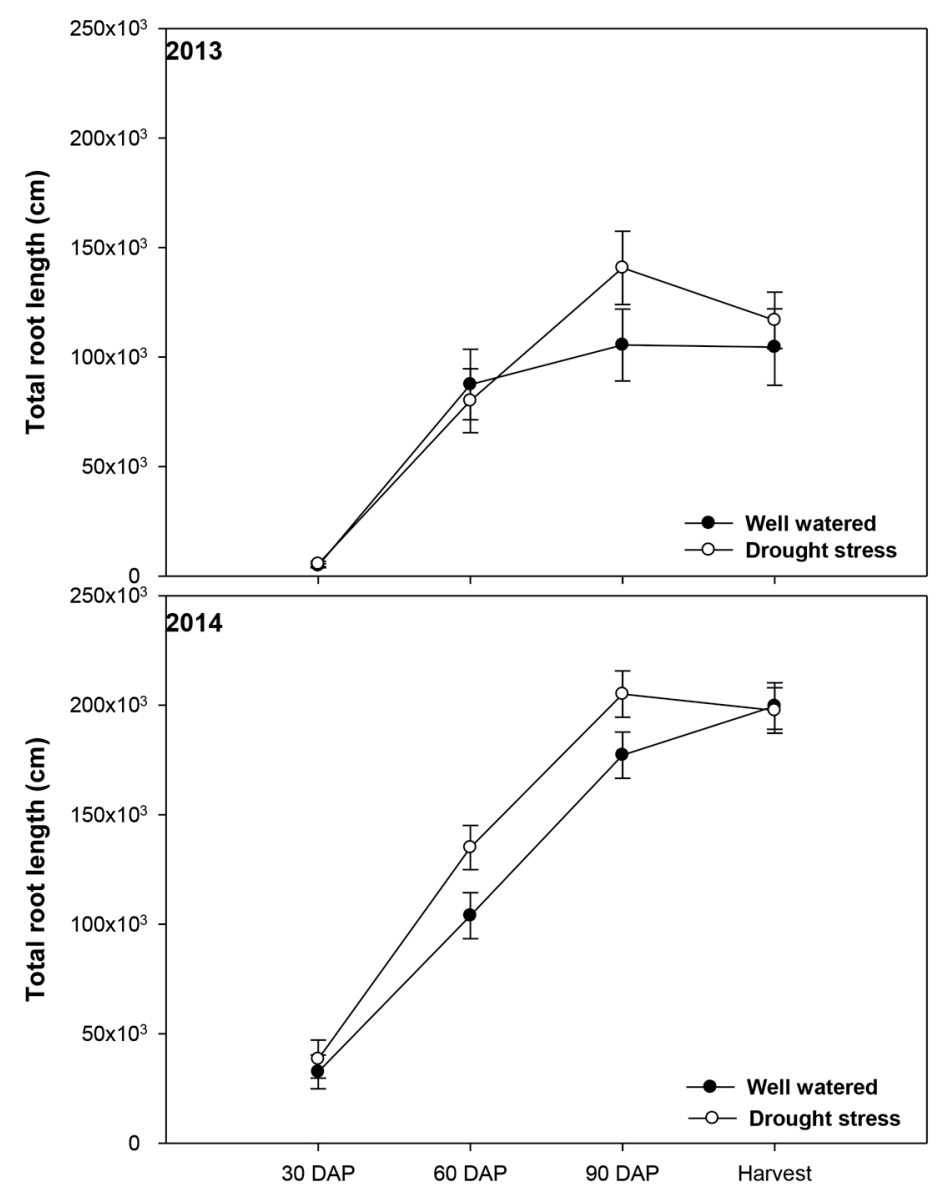

Moreover, CSSL\#1,\#4,\#5,\#6,\#12,\#14 and \#15 tended to be greater in root depth than 'KDML105' under severe stress. At recovery stage, the CSSL\#1,\#4,\#5,\#6,\#10,\#12 and \#15 maintained root branching at upper soil layer and greater recovery from drought stress. In the early drought stress not only maintaining root and shoot growth but also recovery phase would be the most important. The ability of root branching after rewatering of 'KDML105' and root depth during water deficit of donors (DH103 and DH212) were transferred to progenies CSSL\#6, \#10 and \#12. It is confirmed that root branching and root depth were the important traits under unpredictable water deficit. Thus, CSSLs can be used as promising lines for breeding material.

\section{ACKNOWLEDGEMENTS}

This research was funded by the Thailand Graduate Institute of Science and Technology (TG-CPMO-22-12-56-003D), the Cluster Program Management of National Science and Technology Development Agency (NSTDA) (Project code: P1201480), with some support from the Research Centre of Plant Breeding for Sustainable Agriculture of Khon Kaen University (KKU). The authors thank Dr. J. Schiller of the University of Queensland, Australia, for proof reading the manuscript. The authors are also indebted to the Thailand Research Fund (TRF) (Project code: IRG5780003) of KKU and the Faculty of Agriculture, KKU, for providing financial support for manuscript preparation activities. 
Figure 5. Root length density (RLD) at six soil depths and \% RLD of 'KDML105' chromosome segment substitution lines (CSSLs) and their parents under well-watered (WW) and drought stress (DS) at $60 \mathrm{~d}$ after planting in 2013.

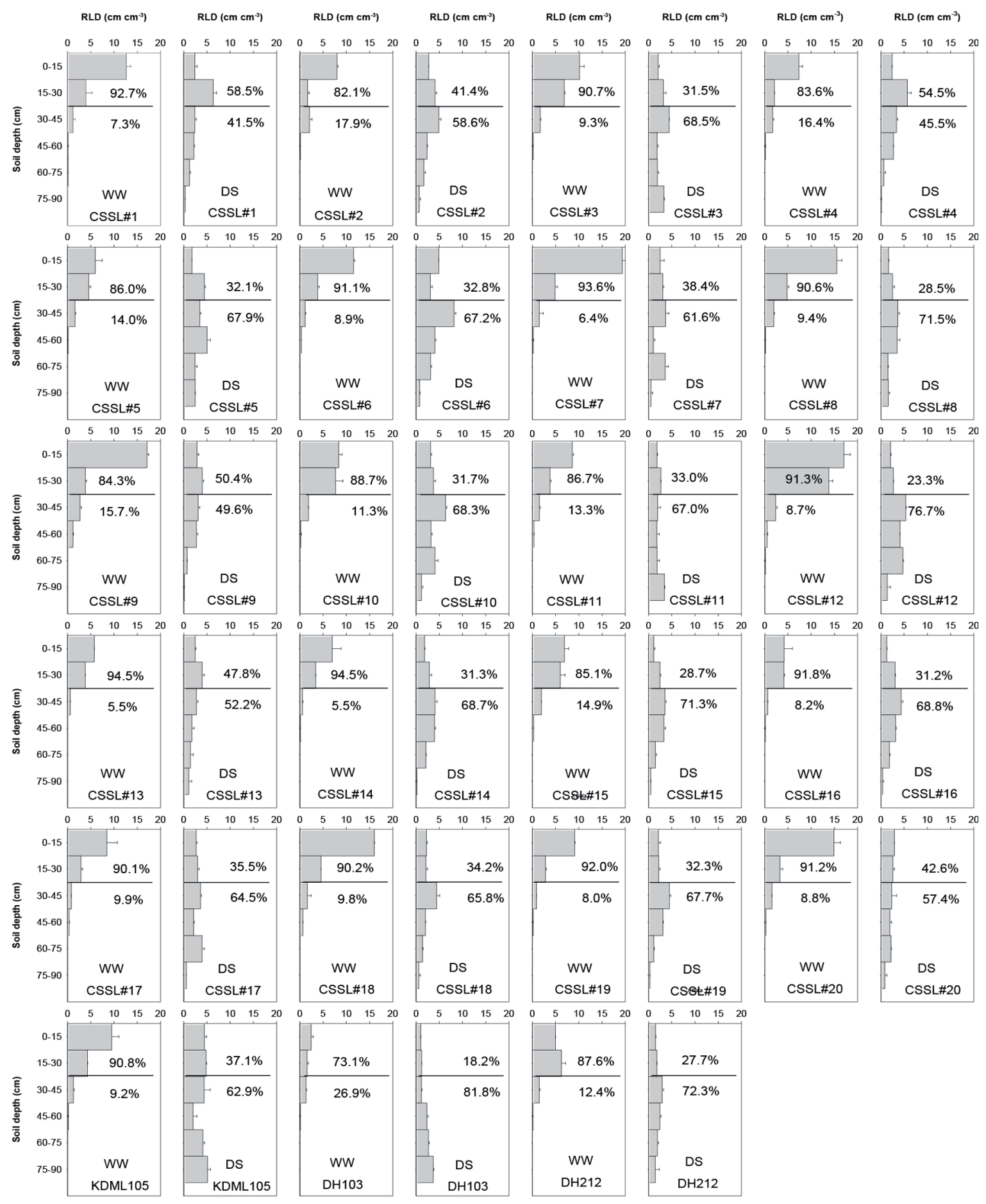


Figure 6. Root length density (RLD) at six soil depths and \% RLD of 'KDML105' chromosome segment substitution lines (CSSLs) and their parents under well-watered (WW) and drought recovery (DR) at $90 \mathrm{~d}$ after planting in 2013.

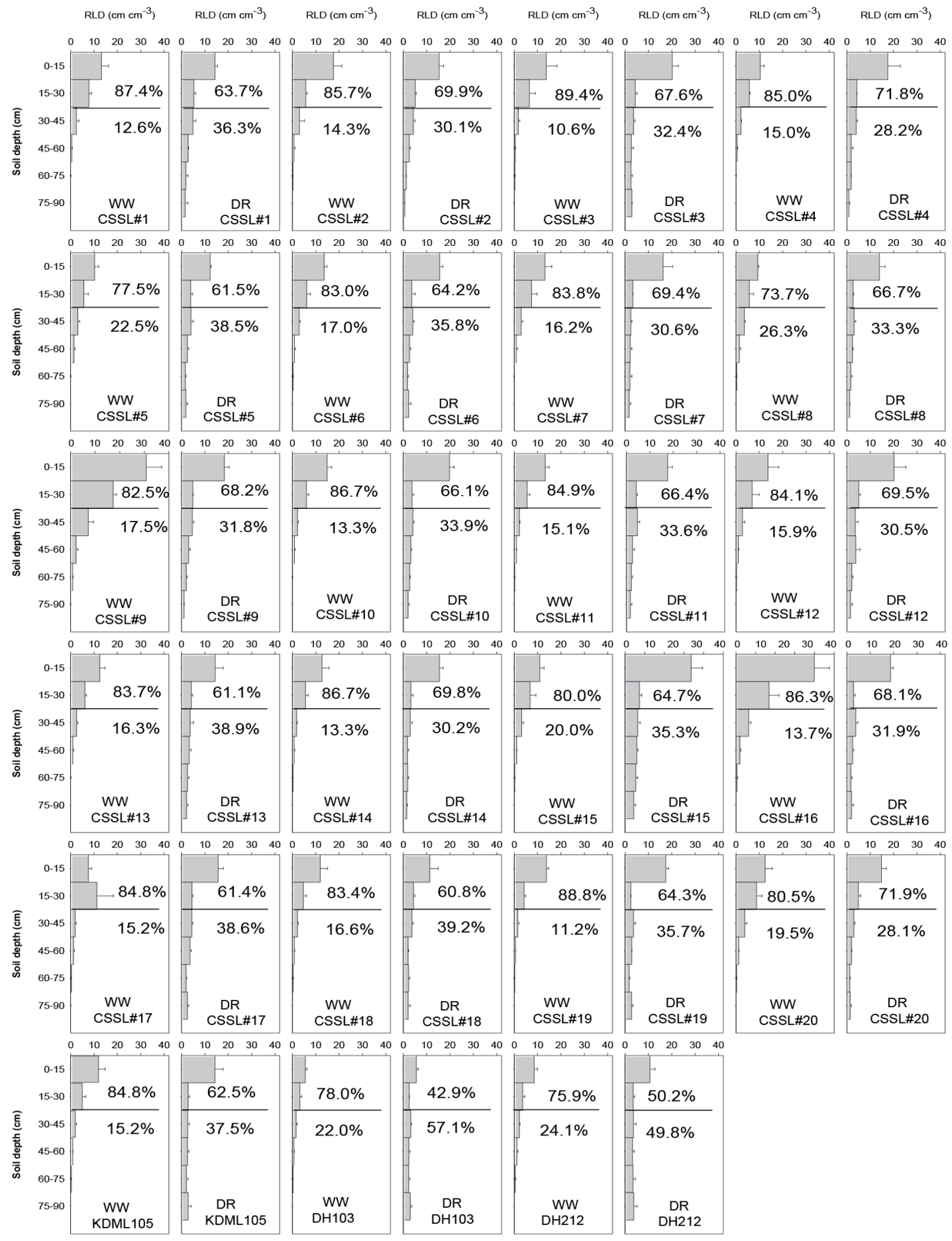


Figure 7. Root length density (RLD) at six soil depths and \% RLD of 'KDML105' chromosome segment substitution lines (CSSLs) and their parents under well-watered (WW) and drought stress (DS) at $60 \mathrm{~d}$ after planting in 2014.

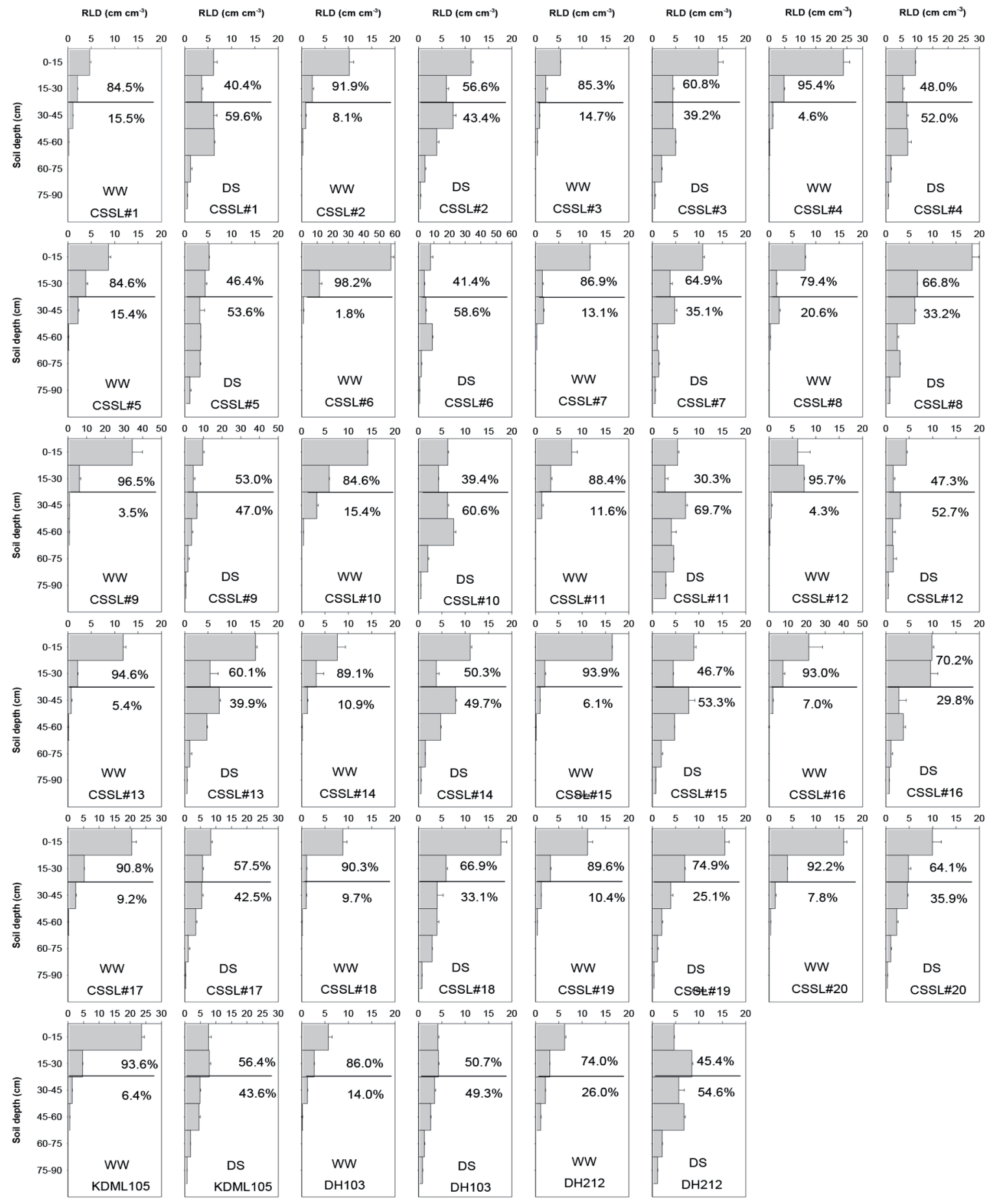


Figure 8. Root length density (RLD) at six soil depths and \% RLD of 'KDML105' chromosome segment substitution lines (CSSLs) and their parents under well-watered (WW) and drought recovery (DR) at $90 \mathrm{~d}$ after planting in 2014.

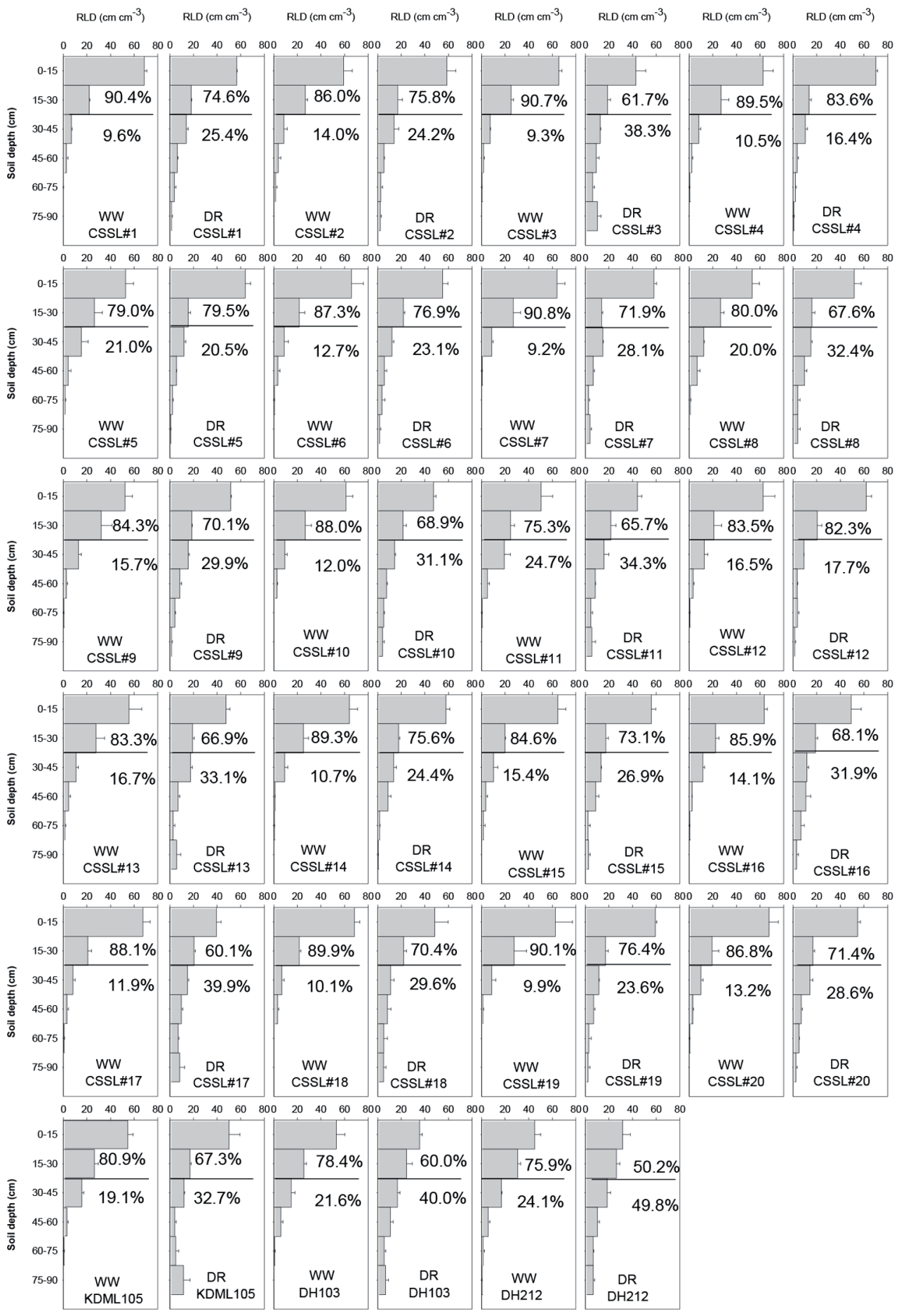




\section{REFERENCES}

Boonjung, H., and Fukai, S. 1996. Effects of soil water deficit at different growth stages on rice growth and yield under upland conditions. 1. Growth during drought. Field Crops Research 48:37-45.

Cabuslay, G.S., Ito, O., and Alejar, A.A. 2002. Physiological evaluation of responses of rice (Oryza sativa L.) to water deficit. Plant Science 163:815-827.

Chaves, M.M., Flexas, J., and Pinheiro, C. 2009. Photosynthesis under drought and salt stress: regulation mechanisms from whole plant to cell. Annual Botany 103:551-560.

Chen, J., Bughio, H.U.R., Chen, D.Z., Liu, G.J., Zheng, K.L., and Zhuang, J.Y. 2006. Development of chromosome segment substitution lines from a backcross recombinant inbred lines population of interspecific rice cross. Rice Science 13(1):15-21.

Comas, L.H., Becker, S.R., Cruz, V.M.V., Byrne, P.F., and Dierig, D.A. 2013. Root traits contributing to plant productivity under drought. Frontiers in Plant Science 4:1-16.

DaMatta, F.M., and Ramalho, J.D.C. 2006. Impacts of drought and temperature stress on coffee physiology and production: a review. Brazilian Journal of Plant Physiology 18(1):55-81.

Furuta, T., Uehara, K., Angeles-Shim, R.B., Shim, J., Ashikari, M., and Takashi, T. 2014. Development and evaluation of chromosome segment substitution lines (CSSLs) carrying chromosome segments derived from Oryza rufipogon in the genetic background of Oryza sativa L. Breeding Science 63:468-475.

Gomez, K.A., and Gomez, A.A. 1984. Statistical procedures for agricultural research $2^{\text {nd }}$ ed. John Wiley and Son, New York, USA.

Gowda, V.R.P., Henry, A., Yamauchi, A., Shashidhar, H.E., and Serraj, R. 2011. Root biology and genetics improvement for drought avoidance in rice. Field Crops Research 122:1-13.

Hazra, K.K., and Chandra, S. 2014. Mild to prolonged stress increased rice tillering and source-to-sink nutrient translocation under SRI management. Paddy Water Environment 12:245-250.

Jongdee, B., Pantuwan, G., Fukai, S., and Fischer, K. 2006. Improving drought tolerance in rainfed lowland rice: An example from Thailand. Field Crops Research 80:225-240.

Junjittakarn, J., Girdthai, T., Jogloy, S., Vorasoot, N., and Patanothai, A. 2014. Response of root characteristics and yield in peanut under terminal drought condition. Chilean Journal of Agricultural Research 74(3):249-256.

Kameoka, E., Suralta, R.R., Mitsuya, S., and Yamauchi, A. 2016. Developmental plasticity of rice root system grown under mild drought stress condition with shallow soil depth; comparison between nodal and lateral roots. Plant Production Science 19(3):411-419.

Kamoshita, A., Babu, R.C., Boopathi, N.M., and Fukai, S. 2008. Phenotypic and genotypic analysis of drought-resistance traits for development of rice cultivars adapted to rainfed environments. Field Crop Research 109:1-23.

Kanbar, A., Toorchi, M., and Shashidhar, H. 2009. Relationship between root and yield morphological characters in rainfed low land rice (Oryza sativa L.) Cereal Research Communications 37(2):261-268.

Kanjoo, V., Punyawaew, K., Siangliw, J.L., Jearakongman, S., Vanavichit, A., and Toojinda, T. 2012. Evaluation of agronomic traits in chromosome segment substitution lines of KDML105 containing drought tolerance QTL under drought stress. Rice Science 19(2):117-124.

Kato, Y., and Okami, M. 2010. Root growth dynamics and stomatal behavior of rice (Oryza sativa L.) grown under aerobic and flooded conditions. Field Crop Research 117:9-17.

Kim, Y.S., and Kim, J.K. 2009. Rice transcription factor AP37 involved in grain yield increase under drought stress. Plant Signaling and Behavior 4(8):735-736.

Lanceras, J.C., Pantuwan, G., Jongdee, B., and Toojinda, T. 2004. Quantitative trait loci associated with drought tolerance at reproductive stage in rice. Plant Physiology 135:1-16.

Lemoine, R., Camera, S.L., Atanassova, R., Dédaldéchamp, F., Allario, T., Pourtau, N., et al. 2013. Source-to-sink transport of sugar and regulation by environmental factors. Frontiers in Plant Science 4:272-292.

Monkham, T., Jongdee, B., Pantuwan, G. Sanitchon, J., and Fukai, S. 2015. Genotypic variation in grain yield and flowering pattern in terminal and intermittent drought screening methods in rainfed lowland rice. Field Crops Research 175:26-36.

Nakata, M.K., Inukai, Y., Wade, L.J., Siopongco, J.D.L.C., and Yamauchi, A. 2011. Root development, water uptake, and shoot dry matter production under water deficit condition in two CSSLs of rice: Functional roles of root plasticity. Plant Production Science 14(4):307-317.

Niones, J.M., Suralta, R.R., Inukai, Y., and Yamauchi, A. 2012. Field evaluation on functional roles of root plastic responses on dry matter production and grain yield of rice under cycles of transient soil moisture stress using chromosome segment substitution lines. Plant and Soil 359:107-120.

Okami, M., Kato, Y., Kobayashi, N., and Yamagishi, J. 2015. Morphological traits associated with vegetative growth of rice (Oryza sativa L.) during the recovery phase after early-season drought. European Journal of Agronomy 64:58-66.

Pandey, V., and Shukla, A. 2015. Acclimation and tolerance strategies of rice under drought stress. Rice Science 22(4):147-161.

Polania, J., Rao, I.M., Cajiao, C., Grajales, M., Rivera, M., Velasquez, F., et al. 2017. Shoot and root traits contribute to drought resistance in recombinant inbred lines of MD 23-24 $\times$ SEA 5 of common bean. Frontiers in Plant Science 8:1-18. 
Polthanee, A., Promkhumbut, A., and Bamrungrai, J. 2014. Drought impact on rice production and farmers' adaptation strategies in Northeast Thailand. Environmental and Rural Development 5:45-52.

Saha, S., Stelly, D.M., Raska, D.A., Wu, J., Jenkins, J.N., McCarty, J.C., et al. 2012. Chromosome substitution lines: concept, development and utilization in the genetic improvement of upland cotton. p. 107-124. In Ibrokhim, A. (ed.) Plant breeding. InTech, Rijeka, Croatia.

Saleth, R.M., Inocencio, A., Noble, A., and Ruaysoongnern, S. 2009. Economic gains of improving soil fertility and water holding capacity with clay application: the impact of soil remediation research in Northeast Thailand. Journal of Development Effectiveness 1(3):336-352.

Shim, R.A., Angeles, E.R., Ashikari, M., and Takashi, T. 2010. Development and evaluation of Oryza glaberrima Steud. chromosome segment substitution lines (CSSLs) in the background of O. sativa L. cv. Koshihikari. Breeding Science 60:613-619.

Siangliw, J.L., Jongdee, B., Puntuwan, G., and Toojinda, T. 2007. Developing KDML105 backcross introgression lines using marker-assisted selection for QTLs associated with drought tolerance in rice. ScienceAsia 33:207-214.

Uphoff, N., Fasoula, V., Iswandi, A., Kassam, A., and Thakur, A.K. 2015. Improving the phenotypic expression of rice genotypes: rethinking "intensification" for production systems and selection practices for rice breeding. The Crop Journal 3:174-189.

Wopereis, M.C.S., Kropff, M.J., Maligaya, A.R., and Tuong, T.P. 1996. Drought-stress responses of two lowland rice cultivar to soil water status. Field Crops Research 46:21-39.

Xu, Z., Zhou, G., and Shimizu, H. 2010. Plant responses to drought and rewatering. Plant Signaling and Behavior 5(6):649-654.

Yao, Y.Z. 2015. Effects of ridge tillage on photosynthesis and root characters of rice. Chilean Journal of Agricultural Research 75:35-41.

Zhu, W., Lin, J., Yang, D., Zhao, L., Zhang, Y., Zhu, Z., et al. 2009. Development of chromosome segment substitution lines derived from backcross between two sequenced rice cultivars, Indica recipient 93-11 and Japonica donor Nipponbare. Molecular Biology Reports 27:126-131. 